



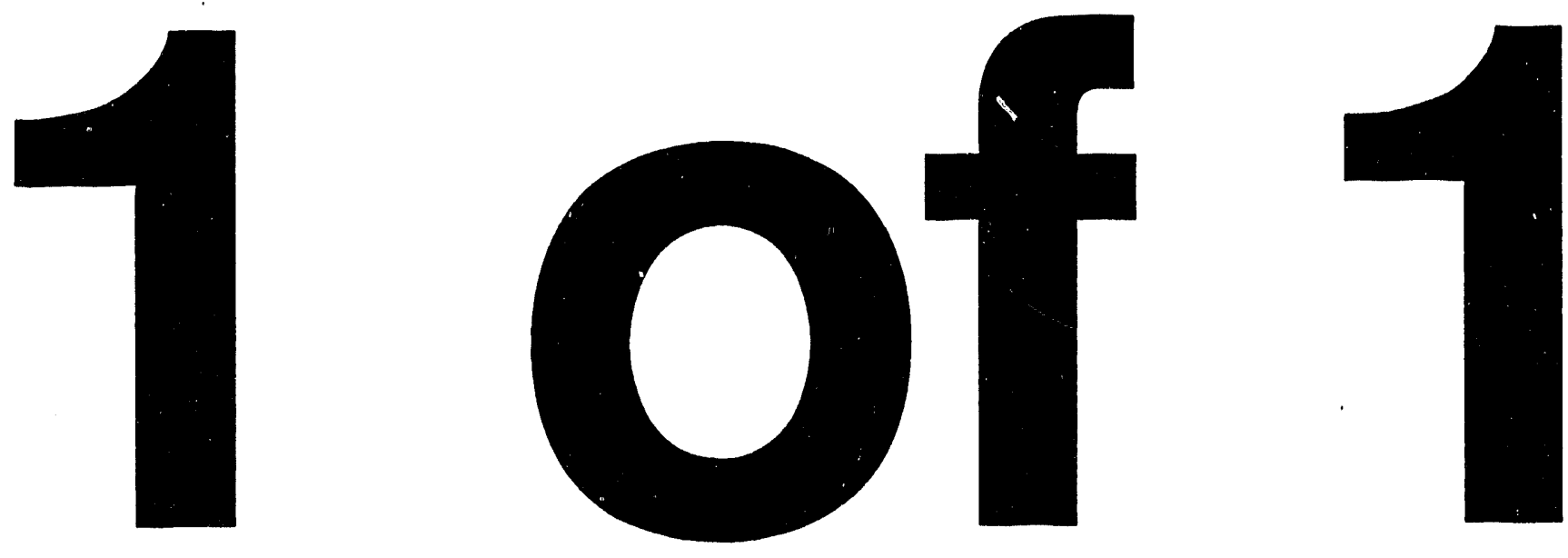


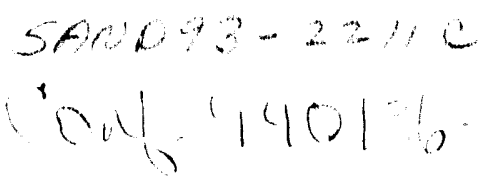

\title{
TECHNOLOGY TRANSFER AT SANDIA NATIONAL LABORATORIES
}

October 1, 1993

Mark S. Allen \& Dan E. Arvizu

Sandia National Laboratories

Albuquerque, New Mexico 87108

\begin{abstract}
Transferring technology to the private sector to help improve the competitiveness of key U.S. industries is now an official mission of the U.S. Department of Energy's (DOE) defense program national laboratories. We believe that national laboratories can play an important role in addressing U.S. industrial competitiveness. Sandia is seeking to match laboratory strengths with industry-defined market needs in targeted industrial sectors. Sandia, like other national and federal laboratories, is developing an aggressive technology transfer program. This paper provides a brief review of our program and provides a snap-shot of where we are at today.
\end{abstract}

This work was supporled by the United

States Department of Energy under

Contract DE-ACก4-94ALR5ONO.

\section{DISCLAIMER}

This report was prepared as an account of work sponsored by an agency of the United States Government. Neither the United States Government nor any agency thereof, nor any of their employees, makes any warranty, express or implied, or assumes any legal liability or responsibility for the accuracy, completeness, or usefulness of any information, apparatus, product, or process disclosed, or represents that its use would not infringe privately owned rights. Reference herein to any specific commercial product, process, or service by trade name, trademark, manufacturer, or otherwise does not necessarily constitute or imply its endorsement, recommendation, or favoring by the United States Government or any agency thereof. The views and opinions of authors expressed herein do not necessarily state or reflect thuse of the United States Government or any agency thereof. 


\section{Economic Competitiveness: A National Perspective}

At this point in world events, national security and economic competitiveness are becoming increasingly intertwined. In today's competitive international environment, the transfer of federally funded technologies must be managed so that their benefits accrue preferentially to U.S. manufacturers. Traditionally, all federally funded research has been held to be a public good whose benefits are the property of everyone, and the results have been openly and widely disseminated. In the past, when a federal laboratory discovered and published an exciting new technology, the only industries capable of taking advantage of it were usually U.S. industries. But with the new fierce competitiveness of foreign industries, this is no longer the case. Today, major developments published by federal laboratories in the public domain -- especially developments in high technology areas such as microelectronics, computers, and factory automation -- are most likely to be adopted first by a foreign company that has considerably more resources than U.S. companies to invest in long-range technology development. The press has given high visibility to the commercial success of some overseas companies that have capitalized on technology developed in the U.S.

Though the terms economic competitiveness and technology transfer are used increasingly today, the exact meaning of these terms remains somewhat ambiguous. Typically, economic competitiveness is used in the context of the declining market share of key US. industries in the international marketplace; technology transfer, in this context is the process of moving science and technology out of the laboratory and onto the factory floor. Recently, several blue-ribbon commissions on competitiveness ${ }^{1-5}$ reported that many U.S firms are being outperformed in the design and manufacture of reliable, high-quality products and that U.S. industry generally is ineffective in transferring technology from its own research organizations to its manufacturing organizations. The commissions also point to a general lack of cooperation -- perhaps even adversarial relationships -- that accounts for ineffective technology transfer between government, universities, and industry. They report that we need to do better on many fronts, including improving education and work-force skills, reducing the cost of capital, lengthening planning horizons, and paying more attention to quality management principles.

Given these reports, there is widespread agreement throughout the U.S. Government about the need to increase the rate at which our nation's efforts in research and development are transferred to the industrial sector. Much work is being done by the Departments of Defense (DOD), Energy (DOE), Commerce (DOC), the National Aeronautics and Space Administration (NASA), and the office of Science and Technology Policy (OSTP) to identify and develop plans for technologies critical to our nation's well-being. All of the various $g$,vernmental agencies agree there 
are several critical technology areas that are important to our nation's ability to compete, including high performance materials, supercomputing, intelligent machines, microelectronics, and photonics.

With the urgency of their missions and the reality of the budget deficits, the various federal agencies are beginning to pull together to maximize the return on the taxpayer's investments. NASA has established six Regional Technology Transfer Centers throughout the United States that can serve as technology outlets for many DOD and DOE labs. Additionally, some individuals have suggested that DOC's National Institute of standard's and Technology's (NIST) manufacturing centers be used to showcase the advanced manufacturing capabilities of the DOE laboratories and plants.

\section{Sancia National Laboratories: A Brief History}

Sandia National Laboratories, originally known as the sandia Laboratory, was operated by the University of California from its founding in 1945 until 1949, when AT\&T accepted responsibility for the Laboratory's operation at President Truman's request. Sandia Corporation was operated as a wholly owned subsidiary of AT\&T until October 1, 1993 for the U.S. Department of Energy (DOE) on a no-profit, no-fee basis. On october 1, 1993, the Martin Marietta Corporation began managing Sandia Corporation. Sandia's headquarters and main laboratory are located in Albuquerque, New Mexico. Another laboratory complex is located in Livermore, California, with additional facilities near Tonopah, Nevada, and on the island of Kauai, Hawaii.

Although DOE projects continue to reseive top priority, sandia also does work for other federal agencies, including the Department of Defense. During the past twenty years, Sandia has evolved from a laboratory with a single mission to one with many programs. With the arrival of the energy crisis in the early 1970s, Sandia began to take on increasing responsibilities in the field of energy research for the DOE. Sandia's research has included fossil fuel recovery and use, and alternate energy technologies, especially nuclear and renewable energy sources (i.e., solar and wind). In the 1980s, Sandia also took on additional responsibilities for the DOD in areas such as advanced military technology, intelligence, arms control, and verifying compliance with arms control treaties.

Today, Sandia's role as a national laboratory cuntinues to evolve in step with changing conditions in the world's geopolitical, environmental, and economic climates. Many factors have affected Sandia's present and future role. They include: 1) The end of the cold war; 2) The success of advanced technologies during Kuwait's recent liberation; 3) Revised requirements that will produce a reduced, safer national stockpile of nuclear armaments; 4 ) Demands for the development of environmentally benign 
manufacturing processes and the safe disposition of nuclear waste; 5) The likelihood of future energy crises; and 6) Increased efforts to improve the ability of U.S. manufacturers to compete effectively with their international counterparts.

\section{Sandia National Laboratories: what Does it Have to offer U.s. Industry?}

As a result of its work on components for the nation's nuclear weapons program, sandia scientists and engineers have developed a broad base of knowledge in the fields of materials science, computational and engineering science (e.g., fluid mechanics, heat transfer, aerodynamics), solid state science, radiation-hard microelectronics (e.g., microelectronics whose functions are unaffected by ionizing radiation), and unique testing capabilities under harsh environments. These technologies have evolved during the past four decades, with increasing emphasis on nuclear safety, reliability, and security. Some of our nonnuclear work has helped us develop unique capabilities with sensors, data management, satellites, lasers and pulsed power, massively parallel processing techniques, energy and environmental technologies, robotics, and a multitude of manufacturing processes.

\section{Technology Transfer Is Not New To Sandians}

A review of the history of technology transfer at the national laboratories could support the argument that they have been relatively successful at transferring laboratory-developed technology to the private sector. Indeed, most laboratories can point to major technology transfer successes as evidence that federally developed technology has been applied to improving U.S. industrial competitiveness.

A clear example of such a success at Sandia is the Sandia-developed laminar-flow clean room technology patented in 1964. The technology was developed originally to help establish production standards for subcontractors who manufactured radiation-tolerant inicroelectronics circuits for the U.S. Department of Defense. But NASA quickly saw the value of the technology and asked Sandia's help in adapting the concept to the needs of the space program. Sandia's news releases and a Time magazine article featuring the clean-room technology produced a flood of inquiries about it, and in quick succession Sandia transferred the technology to RCA for use in its color-picture tube plant, to Zenith for a similar purpose, and to Western Electric for use in the production of printed circuit boards. By 1966, laminar flow technology was quickly coming into widespread use in the U.S. and was getting started in Europe. By 1972, laminar flow equipment was in widespread use in Japan, Europe, Australia, Asia, and Africa. Today, the laminar-flow clean room business is a five-billion-dollar per year business and is used 
in the production of numerous pharmaceutical products, in many hospital operating rooms, and in virtually every microcircuit manufacturing facility in the world.

Sandia's hot-air solder leveler had a similar broad impact. Invented and refined in the early seventies to meet military requirements for printed-circuit boards designed for the VELA satellite detection system, the hot-air solder leveler coats and levels solder on printed-circuit boards, allowing them to be made more easily and with fewer failures. Today hot-air leveling saves the circuit-board industry an estimated $\$ 250$ million a year, and dozens of companies are manufacturing levelers or offering leveling services to printed circuit-board makers. AT\&T's Richmond, Va., printed wiring products facility reports that about 70 to 75 percent of the plant's production undergoes hot air leveling (the extremely thin coating produced by the leveler is not appropriate for some applications).

The Combustion Research Facility (CRF) at Sandia's Livermore location began operation in 1980. It is one of the DOE's most successful user facilities in terms of industry participation. It maintains a highly specialized set of laser-diagnostic and supercomputer-driven analytical capabilities for evaluating combustion processes that make possible high-value-added collaborative efforts with companies that manufacture products related to combustion processes (automotive, aerospace, coal and petroleum, and heating). From the time it began operations, hundreds of industrial visitors have interacted with CRF researchers. More than 50 long-term (i.e., longer than one month) visiting industrial scientists from 33 companies have collaborated with DOE-sponsored Sandia researchers. On average, the cost of the work is shared equally by the DOE and industry. There are currently 75 long-term visiting scientists from industry and academia at the CRF.

As one example of a CRF collaboration, the Rotary Engine Division of John Deere Technologies International in Livermore has completed a cooperative project to characterize the fluid motion in a prototype rotary engine. In addition to John Deere, this effort has been supported jointly by the Gas Research Institute and DOE'S Energy Conversion and Utilization Technologies Program. John Deere complemented the CRF's scientific capabilities by providing expert knowledge about rotary engine design, development, and testing. The optically accessible test engine was designed and built in New Jersey, using window design technology developed at Sandia, and was then shipped to the CRF. John Deere sent a staff member to the CRF for the duration of a four-month experiment. The experiment involved the use of laser Doppler velocimetry to measure gas velocities and turbulence intensities in the engine's combustion chamber. This successful collaboration is expected to build a technology base that will lead to more cooperative efforts with other U.S. manufacturers of internal combustion engines. We have already worked with Ford Motor Company, General Motors, and 
Chrysler Corporation.

The specialty metals industry produces alloys that define the high-temperature and high-stress limits of jet engines, chemical plants, valves and pipes in nuclear reactors, plus many other products. Although the specialty metals industry is small, its output is critical to much larger industries such as aerospace, petrochemical, and energy production. Because material quality and price dominate the competitive position of products from this industry, new research tools are needed to improve current manufacturing processes. In October 1988, a group of U.S. producers and users of specialty metals formed the specialty Metals Processing Consortium (SMPC), specifically to work with Sandia on precompetitive generic research has led to improved production processes. The cost of this work is being shared by industry and the DOE, with industry picking up more than half the tab. Work began on July 18, 1990, when an agreement was signed by the DOE and SMPC. The research is being conducted at industry locations as well as at Sandia's vacuum arc remelt facility--the only large-scale, fully instrumented research furnace in the country. This facility has already been instrumental in developing a new control technique for fabricating high-purity, nickel-based super alloys. We expect the Sandia/SMPC research program to play a major role in keeping the specialty metals industry competitive in domestic and world markets.

\section{TO DATE, SANDIA HAS LEARNED A LESSON OR TWO (OR THREE!)}

A review of Sandia's experiences with technology transfer has provided valuable insight into the primary elements needed to make the relationships between a large multi-program national laboratory and targeted sectors of industry succeed.

First, and most important, is to establish an atmospliere of cooperation and teamwork, and a sense of mutual trust and respect that continues throughout the effort. Second, there must be recognized champions at the laboratory and in industry who act as catalysts and "barrier busters." Third, there must be a significant element of market pull. Market pull is best described as applying technology to solve a specific known problem identified by a commercial partner. The converse is technology push, in which a technology is marketed as a solution looking for a relevant problem. In particular, everyone-- from the top executive to the scientist and engineer at the bench-must recognize the value added by the laboratory's technology and participation, and the competitive advantages it will give the industry participant. Finally, industrial clients must be thoroughly involved in all aspects of defining the additional research that may be required, and in developing the research and development agenda. In effect, there must be a full, cooperative partnership between the laboratory and its clients. 


\section{Sanaia's New strategic Plan for Technology Transfer}

Clearly, there are no quick or easy solutions to the many complex, interrelated issues affecting U.S. economic competitiveness. An examination of how government's role might relate to the issue of economic competitiveness reveals that government, industry, and academia are each motivated differently. Government's role is to look after the national interest, whether for national defense or economic security. The national laboratories represent government investment in $R \& D$ and were set up to address national security issues. Universities traditionally focus on educating and on broadly advancing the frontiers of science to benefit all humankind. They typically pay little attention to U.S. economic issues. Industry, by necessity, is most interested in profit and loss statements and is motivated to compete company against company -- and only indirectly attends to how business dealings affect the U.S. economy as a whole. Given that a declining U.S. economy has national security implications that cannot be fully addressed by industry or academia individually, it appears that the national laboratories do have an important role to play.

With the passage of the National Competitiveness Technology Transfer Act of 1989, technology transfer became a mission of DOE's defense program laboratories. The Act gave the laboratories the tools and authority to more aggressively pursue cooperative relationships with industry, universities, and state and local governments for the purpose of developing and transferring commercially valuable technologies to the private sector. The legislation also mandated that each DOE laboratory establish an office of Research And Technology Assessment (ORTA) to handle technology transfer and gave the laboratories the authority to enter into industry partnerships via CRADA's -- Cooperative Research and Development Agreements. Sandia and other DOE laboratories are incorporating the CRADA mechanism into new, more aggressive technology transfer programs to carry out their new mission.

Sandia's primary objective for technology transfer is to contribute to the economic security of the United states by transferring sandia-developed technologies that have potential commercial value to U.S. industry. We consider the improvement of the economic security of the U.S. a national security issue -and a natural enhancement of our defense and energy program missions. As we pursue this important new area, we are committed to (1) protecting national security interests, (2) creating lasting value to the taxpayer, (3) providing fairness of opportunity to industry, and (4) following the highest ethical standards to avoid even the appearance of conflicts of interest as we create cooperative programs and perform the work.

Regarding the "how" of technology transfer, we are applying an array of mechanisms, including publications, workshops, seminars, technology news releases, and one-on-one interactions. We're also 
using a number of formal mechanisms, such as cooperative R\&D working arrangements, contract work, work-for-others agreements, technical assistance, user facilities, personnel exchanges, and intellectual property licensing. We are currently working with DOE to help streamline these formal processes to make them more flexible and efficient.

To achieve the full potential of a national laboratory we must be more than merely responsive to industry needs; we must aggressively seek out opportunities to partner with industry. At Sandia, we are targeting commercially oriented industries in fields (in which Sandia has superior expertise) that are strategic to our national security and critical to solving problems of prime national importance.

\section{The sandia ORTA Goal: To be the Leader in Technology Transfer Theory and Practice}

\section{INTRODUCTION}

At Sandia, we believe that we have a lot to offer U.S. industry. To maximize the number of high quality technology transfer partnerships, Sandia has assembled an entrepreneurial technology transfer team and encouraged them to be aggressive and innovative.

ORTA INFRASTRUCTURE

To carry out its mission, Sandia established product Area Engineering (PAE) function. To our customers (our technical line, industry, and DOE), the PAE's are technology transfer. In other words, the PAE is the focal point for all technology transfer planning, activities, and interactions within specific technology areas at Sandia (figure 1). Currently, the PAE's are divided along five lines of technology:

- Computer Architecture \& Applications

- Energy \& Environment

- Advanced Manufacturing

- Microelectronics \& Photonics

- Advanced Materials.

Each PAE typically has a technical graduate degree and a Master's in Business Administration. They usually have experience in industry as well as a broad knowledge of the laboratory.

To accomplish their mission, the PAE's are supported by functional experts within the ORTA. This support is illustrated in Figure 2. Through this functional support, they also have access to expertise outside sandia when necessary. In summary, the PAE serves as a catalyst, facilitator, consultant, leader, and supporter to enable an effective technology transfer program at the laboratory. 
TECHNOLOGY TRANBFER IS THE LINES JOB

One of the first things we teach new members of the ORTA is that their job is not to do technology transfer. Rather, it is to facilitate the process of technology transfer. The front lines of technology transfer are staffed by Sandia's technical personnel.

As such, it is the ORTA's job to teach the line the basic of technology transfer. To this end, we have assembled a collection of eleven courses for our technical staff that cover the basics:

Introduction to Technology Transfer

Cooperative Research \& Development Agreements

Commercial Work For others Agreements

User Facility Agreements

An Introduction to Intellectual Property

Licensing of Intellectual Property

Handling Proprietary Information

Marketing Basics

Building a Technology Transfer Business

Small Business Technology Transfer Mechanisms and Programs obtaining Funding to Perform Technology Transfer

Each class is taught by a PAE. With a cap of 20 , each class (which is offered 6 times a year) quickly fills up.

\section{TOOL UPDATE}

-CRADA's

On January 22,1991, AT\&T, the DOE, and Sandia signed agreements that provided for sandia's entry into CRADA partnerships with industry. With this authorization, a new era of Sandia/industry teaming has began. Although this mechanism is new as of october 1991, over 120 agreements with a dollar value of over $\$ 450$ million have been approved by the DOE to date. In these agreements, the relative cost share is typically 60-percent industry aıd 40-percent DOE, with most of industry's cost share spent in industry.

To give a flavor of the types of CRADA's sandia is working on, two examples follow: Chevron Petroleum Technology company and Signetics. 
Sandia and Chevron are developing an advanced borehole seismic source. By teaming with Chevron, Sandia hopes to help facilitate the recovery of bypassed gas and oil, thus contributing to the economic viability of using US. petroleum reserves. This project joins sandia's expertise in advanced hydraulic systems, hightemperature electronics, and high-frequency seismic receivers with Chevron's experience in oil field operations. The advanced source will be based on a prototype that has already been build and operated by Chevron. The oil and gas industry and others that use geophysical measurements need instrumentation for imaging the region between two boreholes. "Crosswell imaging" is used to determine geologic structure, rock properties, and fluid saturation between the boreholes. The most extensively applied process for crosswell imaging requires the use of a seismic source in one borehole and a seismic receiver in the other. current seismic sources have one or more of the following limitations: low output force, low frequency output, only one polarization output, low temperature operation, or difficult deployment. The object of this project is to build an advanced borehole seismic source that has a 6000-pound out force, a 5-1440 Hertz output frequency, three-polarization output, hightemperature operation (400 degrees F), and easy deployment on a wire line with no hoses.

Sandia is working with signetics to develop improved technologies for integrated circuit (IC) manufacture. Signetics will manufacture wafers in a next-generation, 1.0 micron, complementary metal oxide silicon IC production technology. Sandia will use its test systems, reliability model, and expertise to assess the reliability of the ICs and identify the strengths and weaknesses of the signetics technologies. Sandia will also provide advanced failure analysis support to analyze any problems discovered in the technology. Signetics will use these results to improve its technology during development, prior to full scale production. Higher levels of IC reliability achieved in shorter time frames will results in reduced costs and improved customer satisfaction.

-COMMERCIAL WORK-FOR-OTHERS

Any non-DOE entity can attempt to hire sandia under our work-Forothers program. Under the WFO's program, industry can, under certain conditions (such as uniqueness), hire the laboratories to help with product and/or process commercialization. Often times, it is advantageous for a company to "rent" a capital intensive facility or a world-class technical expert from a national lab rather than try to duplicate the facility or hire the individual themselves. Today, only about $2 \%$ of Sandia's total WFo program comes from the industrial sector (the rest comes from other federal agencies). However, this year, Sandia has seen an increase in absolute dollars in the commercial WFO's over last year. As U.S. industries' corporate R\&D budgets are being cut, U.S. companies can leverage their dollars by working with the national labs. 
One of our more prominent WFO agreements at Sandia is with

sematech. U.S. semiconductor manufacturing companies, which once dominated world semiconductor equipment markets, are being challenged by serious foreign competition that is rapidly eroding the industry's world market share. To counter this serious threat, sematech, a consortium of 14 major U.S. semiconductor manufacturers, has entered into a work-For-Others arrangement with Sandia. Sandia is developing a semiconductor Equipment Technology Center whose mission is to help manufacturers of integrated circuit processing equipment develop advanced equipment and processing techniques. Our long-term objective is to set up a methodology that can be used to design reliability into equipment. Sandia is uniquely suited for this challenge because of its extensive technology base developed in semiconductor process modeling and measurements and its reliability programi in nuclear weapon and nuclear power-plant programs. Sandia also has ongoing research efforts in manufacturing processes such as chemical vapor deposition, plasma processing, and ion implantation.

\section{- IICENSES}

Successful licensing of research results created in national and federal laboratories is difficult. Often, the "product" to be licensed is not developed in response to commercial market need, the technology is very embryonic with uncertainty as to whether it will work reliably outside the laboratory environment, and the financial risk to the licensee in bridging such embryonic technology to market is typically very significant. The licensee must anticipate what competing products will exist some years in the future (when the licensed product finally reaches the market), and have faith that their product can gain sufficient market share to justify the development, manufacturing, and marketing investment. The up-front and advanced royalty payments are typically inconsequential when compared to the other required investments.

Given the aforementioned challenges, it is no wonder that Sandia's cumulative licensing program up through December of 1992 generated about $\$ 60,000$ of revenues (note is not $\$ 60,000$ per year but $\$ 60,000$ since 1945). Similar sized research and development institutions with mature licensing programs typically generate about 5 - $10 \%$ of their yearly $R \& D$ budget in royalties. Given Sandia's FY93 operating budget of $\$ 1.4$ billion, we realize we have a challenge ahead.

In January of 1993, Sandia began aggressively building its licensing program. In general, we try to license all of our irtellectual property on a non-exclusive basis. We grant exclusive licenses only in very rare circumstances (e.g. if the licensee needs an exclusive position to attract financing). If the license is exclusive, we try to put on a field of use or time restriction. So far this year, we have generated over $\$ 200,000$ in royalty revenues. All the dollars that come back to the 
national labs are used to recoup our costs. Any excess funds are returned to the U.S. treasury. Although many companies argue that Sandia should not charge any royalties for our licenses, we believe chat we owe it to the taxpayers to reduce the cost of new technology development. Hence, while the royalty rates in our license agreements are definitely less that prevailing market rates, they are by no means zeroed out. Although the $\$ 200,000$ we have collected this year is quite a ways from the $\$ 100$ million per year goal set recently by Sandia, the technology transfer staff is encouraged by the trend.

-USER FACILITIES

In the early 1970's, the DOE came up with the concept of "User Facilities." Basically, User Facilities were established at national laboratories to ensure widespread participation by the scientiflc community in specific areas of research. In December of 1992, Sandia did not have any User Facilities (compared to our sister lab up north -- Los Alamos National Labs -- who had almost. 40) it knew about. As of this writing, Sandia has established 14 User Facilities and has requests in for several more. User Facilities have great potential for developing new and better ways for working with small businesses.

-SMALL BUSINESS INTERACTIONS

one thing Sandia learned early on -- small business have special technology transfer requirements. To address these needs, Sandia created and implemented the Technology-Based Regional Economic Development (TRED) program in summer of 1991.

Initially, the TRED model had two major components -- technology assistance (or teaming), and "widget transfer." In the technology assistance component, SNL's technology resources (expertise, services, and equipment) were made available to companies developing commercial products. In the "widget transfer" component, SNL's intellectual property assets (patents, copyright, mask works) were placed with private sector firms through various partnership intermediaries.

To carry out the TRED program, SNL established strategic relationships with various entities -- including several universities and various business assistance organizations. These entities helped SNL by prequalifying technology transfer requests, notifying businesses of technology opportunities, and providing feedback on the performance of the TRED program.

TRED was successful for two reasons -- 1) personalized attention was given to every technology transfer request, and 2) customer (small business) and community feedback was actively sought. In 1992, TRED expanded and began offering workshops, seminars, and tours. In early 1993, sandia renamed its program to encompass a national scope -- the National Small-Business Technology Exchange Program (NSTEP). Several other DOE laboratories joined the program as DOE began block funding the effort. Currently, NSTEP 
is considering the addition of "mini-CRADA's" ( $\$ 50,000$ cap) to better service the needs of small businesses. To date, TRED and NSTEP have helped our 200 businesses throughout the country.

\section{MISCELLANEOUS}

At Sandia, we understand that leadership cannot be declared, it must be earned. Hence, we are continually trying improve our processes and understanding of technology transfer. To this end, we have two activities being undertaken which are sure to help strengthen our technology transfer program.

First, we are developing the Technology-Information Environment for Industry (TIE-In) network. Using high-speed computers and networks, we intend to develop a remotely accessible intelligent networked system that will make our engineering products and expertise available to businesses throughout the country though a modem. The first prototype of TIE-In will be demoed in october of 1993 .

Second, in order to understand the attitudes, motivations, and perceptions of inventors at the labs that might. become entrepreneurs, SNL has teamed with the University of New Mexico to perform a longitudinal study on its inventors. We hope that by better understanding our technical geniuses, we might be able to better design personnel policies and programs that will help our technology transfer program (e.g. by allowing our technical staff to form start-up companies based on their technologies).

\section{Conclusion}

Transferring technology from the government to the private sector has assumed important new dimensions with the emergence of a new threat to our national security -- namely, the declining competitiveness of key US. industries in world markets. Growing public awareness and fear of this threat has prompted efforts to improve the nation's competitiveness by tapping the national laboratories to support US. industry

As we continue to refine our Technology Transfer Program at Sandia, we will continue to emphasize the importance of working cooperatively with industry, including use of the cost-shared arrangements described above. Our goal for the program is to shape a comprehensive and integrated strategy that will make the best use of Sandia-developed technology in achieving the national goals of improved quality of life for all Americans, continued economic growth, and national security. 


\section{References}

1. Council on Competitiveness (1988). How Competitive is America? Washington, D.C.

2. Council on Competitiveness (1988). Picking up the Pace: The Commercial Challenge to American Innovation. Washington, D.C.

3. Report of the Committee on Science, space, and Technology, House of Representatives one Hundredth Congress, Second Session. Technology Policy and Its Effect on the National Economy. House Report 100-1093. U.S. Government Printing office, 1988.

4. A Report of the Energy Research Advisory Board to the United State Department of Energy (August 1988). Research and Technology Utilization.

5. U.S. Conference of Mayors and Economic Development Administration of the Department of Commerce (October, 1988). Tapping Federal Laboratories and Universities to Improve Local Economies. 

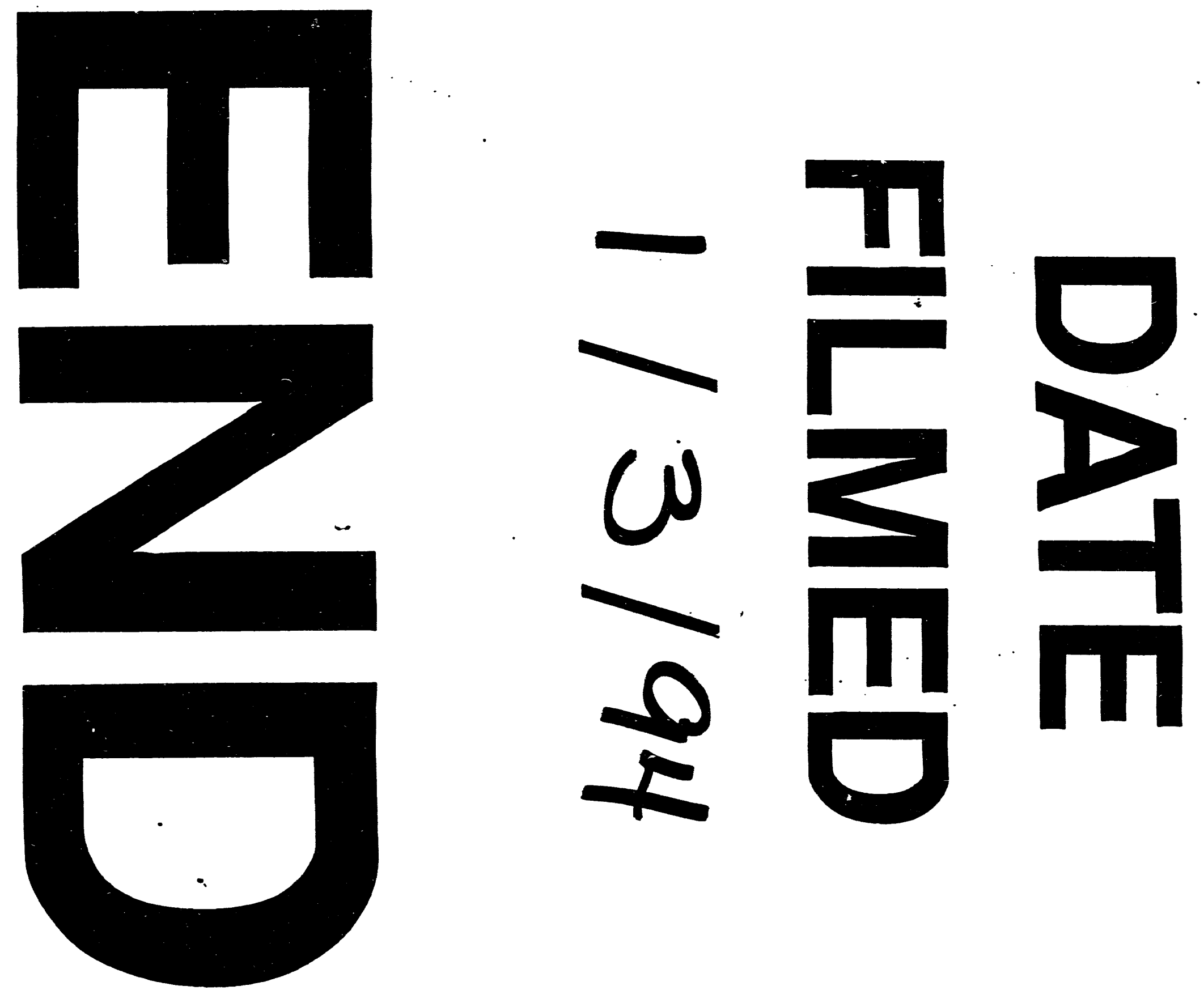
